\title{
Los Montajes de la Temporalidad
}

\section{Editing and Mounting Temporality}

\author{
Carlos Ossa \\ Instituto de la Comunicación e Imagen. Universidad de Chile \\ anis626@yahoo.es
}

Toda forma precisa es un asesinato de otras versiones.

Carl Einstein

Resumen - El presente artículo analiza las relaciones entre historia del arte y modernización, a partir del desplazamiento del positivismo historiográfico por una antropología filosófica de las imágenes, realizado por el historiador alemán Erwin Panofsky. La aparente contradicción entre una visualidad estética y otra técnica sirvió de telón de fondo para una disputa sobre el sentido del tiempo y sus modelos de representación. La disciplina histórica y la lógica modernizadora necesitaban legitimar sus concepciones figurativas y reglas de producción apelando al sentido duradero del pasado o la innovación continua del presente. En este contexto los estudios iconológicos pretenden resistir la degradación del arte causada por una actualidad sin fondo que olvida la herencia cultural y superar un historicismo incapaz de reconocer a las obras artísticas como procesos simbólicos.

Palabras Clave: Erwin Panofsky, historia del arte, modernización, tiempo, iconología.

\begin{abstract}
The following essay analyzes the bonds between Art History and Modernization, from the displacement of the historiographic positivism of German historian Erwin Panofsky. The apparent contradiction between a visual aesthetic and any other technique was a backdrop for a dispute over the sense of time and its representation models. The historical discipline and the Modernization logic needed to validate their figurative conceptions and rules of production by appealing to the everlasting sense of the past or the constant innovation of the present. In this context, the iconological studies seem to resist to the degradation of art caused by a nowadays with no meaning that forgets about cultural heritage and how to overcome an historicism that is able to recognize art works as symbolic processes.
\end{abstract}

Keywords: Erwin Panofsky, Art history, modernization, time, iconology. 
La historia del arte entendida como un sistema estilístico y epocal encontró en la lectura de Erwin Panofsky la posibilidad de convertirse en un dilema humanista. Las obras eran emisarias de un ethos civilizatorio, de una filosofía del hombre que permitía encontrar en objetos estéticos singulares una temporalidad primordial que solo podía leerse descifrando - al modo hegeliano- un espíritu autotélico ubicado más allá de las asperezas de lo histórico contingente. El arte del pasado guardaba una estructura interna abierta a ser examinada por una "conciencia», y Erwin Panofsky suponía que el acontecimiento artístico mostraba su límite temporal fuera de su época, cuando convertido en cultura testificaba su realidad definitiva. En ese momento el arte se desprendía de su tradición y a la vez la consagraba en un devenir que no viene con el lenguaje, pero se hace lenguaje. La influencia de Ernst Cassirer en la concepción del arte como una totalidad de la conciencia fue decisiva en la obra de Erwin Panofsky; ambos asumen, en su lectura de la Crítica del Juicio, la compleja relación que Kant establece entre causalismo y experiencia; orden natural y pensamiento; mundo suprasensible y razón universal. Así, la historia de los «hechos artísticos» no era la proyección interesada de las instituciones que gobiernan el canon ni tampoco la inexorable sombra impuesta por leyes indescifrables. Sin embargo, existe una contradicción entre la idea de un devenir transparente que nos indica la dirección exacta de lo artístico y la operación de desmontaje que el arte ejecuta al agotar los recursos representacionales: donde se ilumina un porvenir se presenta sin anuncio una catástrofe.

La historia del arte que propone Erwin Panofsky se basa en la existencia de un espacio figurativo predeterminado por ideas y estructuras gobernantes del significado general de la producción artística. No existe ya un mundo de suposiciones teológicas dirigiendo el rumbo del arte, sino una comunidad bumana iluminando su desvanecimiento con imágenes auráticas cuyo enigma cabe descifrar a la posteridad. Por esta causa no hay un desmoronamiento del pasado, ni pérdida de su faena porque la continuidad no la da el tiempo, sino el modo de administrar el recuerdo. La coherencia es uno de los principios fundamentales de la metodología usada por el discípulo de Aby Warburg, cuya finalidad es llenar los vacíos de la temporalidad con los requisitos simbólicos de la dialéctica y el aforismo. Las cosas aparecen ante nosotros para notificar la desaparición que las acecha y con ello reclamar una memoria expectante y largas promesas de cognoscibilidad partícipes de un tiempo irreversible. De esta forma la lejanía histórica de las imágenes artísticas es superada mediante una hermenéutica iconológica que reinterpreta y asimila la traza del arte y arrebata a los objetos la connotación invisible en que viven. Esta lectura, en todo caso, se justifica cuando la historia del arte se vuelve inhumana, es decir, un proceso cuya manifestación no tiene escala individual. La finalidad es evitar que el pasado se retire y al secularizar su materia se logra monumentalizar su existencia. El relato histórico puede mostrar la persistencia de los significados y la discontinuidad de los fenómenos. Un ejemplo destacable se encuentra en el libro La Perspectiva como forma simbólica, cuando al analizar el arte del Renacimiento lo caracteriza de acuerdo a un tipo de autoconciencia moderna:

La impresión visual subjetiva había sido racionalizada hasta tal punto que podía servir de fundamento para la construcción de un mundo empírico sólidamente fundado y, en un sentido totalmente moderno, «infinito» (se podría comparar la función de la perspectiva renacentista a la del criticismo y la función de la perspectiva helénica-romana a la del 
escepticismo). Se había logrado la transición de un espacio psicofisiológico a un espacio matemático, con otras palabras: la objetivación del subjetivismo (48).

El arte tiene un modo de escapar al presente que testifica a través de las teorías de la proporción humana ${ }^{1}$, pues de acuerdo a Erwin Panofsky, éstas rebasan la contingencia del método y el oportunismo de la teoría gracias a que ocurren en cualquier época, más allá de su aplicación práctica. La proporción humana remite a la necesidad de dar al cuerpo una destinación simbólica, sea teológica (mundo clásico) o filosófica (mundo moderno) y por lo mismo no está circunscrita al espacio artístico aunque nazca en él. El cuerpo es la civilización y los objetos la remembranza y el pulso. No importa la variedad de movimientos, genios o técnicas artísticas: todos pueden ser reconocidos como adaptaciones y sistematizaciones de procesos capaces de trascender el pensamiento visual y convertirse en esquemas generales de la cultura. La relación entre imagen y pensamiento se «resuelve» a nivel epistemológico, mostrando una historia del arte organizada por una racionalidad iconológica fundada en un sistema de inmanencias que sobrepasan la visibilidad - ya inservible - en que emergieron. ¿Cómo se recupera un sistema cuando el tiempo que debería preservarlo se desgaja a una velocidad inaudita? ¿Qué articulación subyace a la posibilidad de imaginar una historia del arte autoconsciente frente a una modernización expansiva?

La respuesta a este problema la da la morfología de las imágenes ${ }^{2}$ : un diseño determinado por significados inconscientes que trenzan el contenido y la forma a las condiciones universales del discurso y preservan —en el arte- aquella visión de mundo solo dable de leer por las generaciones venideras. Erwin Panofsky propone una historia del arte fundada en una concepción simbólica cerrada sobre sí misma y, a la vez, en espera de su comprensión futura. Las imágenes perduran, gracias a una matriz que las libera del primer instante y pasan de acontecimiento visual a modelo antropológico: incautación de valores humanistas suspendidos en la duración cultural. El historiador no tiene por tarea constatar el origen y la marcha de los fenómenos, sino que encontrar el sentido estructural de la obra negado por los límites de la autoconciencia. Estos límites - propios del artista y su contexto - son el objeto dialéctico a interpretar por una visión crítica persuadida de la existencia de una configuración trascendental de las imágenes artísticas. La operación del autor de Estudios sobre Iconología, elude el positivismo y el psicologismo reinantes en el análisis del arte a principios del siglo XX, y propone una alianza entre visualidad y pensamiento que conduce a la revelación de una coherencia cultural moderna capaz de traducir el pasado y construir sus posibilidades de inteligibilidad. Sin embargo, hablamos de una experiencia de totalidad fugaz, debido a que la continuidad es destruida por las nuevas formas de transmisión cultural fomentadas por la modernización. Esta se

\footnotetext{
El investigador alemán reconoce dos tipos de proporciones: las objetivas, pertenecientes —legítimamentea la representación pictórica sin considerar la importancia de la forma; las técnicas, determinantes en el procedimiento de convertir la voluntad en una obra de arte (kunstwollens).

2 Es conveniente recordar que el programa de estudio de las obras de arte utilizado por Erwin Panofsky consideraba tres etapas: a) la descripción formal a nivel sensible; b) el análisis temático a nivel cultural; c) la significación intrínseca a nivel simbólico. En 1922 el sociólogo alemán Karl Mannheim publicó un artículo titulado "Contribuciones a la teoría de la interpretación de la comsmovisión», donde establece tres niveles de análisis de los fenómenos culturales: a) sentido objetivo; b) sentido expresivo y c) sentido documental. En 1932, Erwin Panofsky reconceptualiza estos niveles — citando expresamente a Mannheim- y consagra la distinción metodológica entre descripción pre-iconográfica, análisis iconográfico e interpretación iconológica.
} 
nutre de la cita y la ruptura de códigos erosionando la validez del «testimonio auténtico» y rompiendo la linealidad con una serie de montajes iconográficos que exacerban un sentimiento por el pasado — cada vez más excepcional y diferido- pero que se convierte en el valor manifiesto a recuperar: el extrañamiento.

La historia del arte, herida por la modernización que la reclama y justifica, se convierte en centinela patrimonial; en arqueología crítica de los efectos visuales de la cultura; en museo discursivo de los prestigios y los géneros; en método de catalogación de lo excéntrico. Ante los descuidos e interrupciones de una vida tecnificada y productiva, donde no hay "arte» ${ }^{3}$, solo imágenes de espacios vencidos que se resisten a caer en su gasto, es fundamental recuperar la imagen y sacarla del torbellino de la usura generado por las industrias del entretenimiento. Sin embargo no es posible, en el ámbito de una sociedad obsesionada con la inmediatez y la ganancia, insistir en la representación, aunque el ejercicio historicista imponga una versión última capaz de detener al objeto estético en una falsa unidad. Una contradicción se hace manifiesta en este plano, pues dos movimientos, en apariencia antagónicos, intentan un control interpretativo de la visualidad. Por una parte, la semejanza entre signo y objeto se deteriora como resultado de la dimensión crítica vanguardista y, por otro, se intenta establecer un realismo trascendental de la experiencia simbólica determinado por reglas causales. Así, se institucionaliza un deseo de controlar la temporalidad del arte y evitar la desorientación de su curso. La modernización necesita un pasado idealizado que no menoscabe su presente unitario y la historia del arte necesita un pasado ideal que domine el presente disperso. Garantizar el orden de la representación y administrar su contenido se convirtieron en tareas comunes de la lógica modernizadora y de la disciplina historiográfica. Ambas buscaban hegemonizar la configuración de lo sensible y dirigir la política de las imágenes de acuerdo a una narrativa de las aclaraciones y las mentalidades (Ankersmit, 2004).

\section{EL NAUFRAGIO DE LA ILUSIÓN}

El capitalismo transformó el estatuto de la visualidad al construir máquinas de visión dependientes de la aceleración del tiempo: convirtió a las imágenes en objetos y discursos de un progreso tecnológico que veía con desprecio lo clásico y arrasaba con los vestigios sin grandes consideraciones. Erwin Panofsky representa a una serie de historiadores del arte alemán (Alois Riegl, August Schmarsow, Aby Warburg, Jacobo Burckhardt, Adolf von Hildebrand, Heinrich Wolfflin, Johan Joachim Wilckelmann) afectados por la violencia de la representación tecnológica que estrena fantasmagorías manipuladas por mecanismos neurológicos, cinemáticos e ingenieriles. Atrás han quedado los escombros históricos que solo la atenta mirada del observador cultural puede reconocer como la gramática generativa que une la voluntad artística con la cosmovisión secular. La historia del arte interrumpe - gracias a su fuero hermenéutico- el trabajo apocalíptico de las imágenes del progreso y urde caminos de lectura para esos artefactos estéticos desperdigados en la vida moderna. Si la naturaleza desaparece en las manos de la técnica, entonces la imita-

En estricto rigor, la iconología es un método filológico que intenta recuperar las constelaciones de escritura depositadas en las imágenes. Imagina que la cultura clásica fue una entidad homogénea y coherente que supo organizar el valor de las cosas y protegerlo con símbolos duraderos y significativos. 
ción de su callada majestad — sugerida por J.J. Wilckelmann ${ }^{4}$ - tiene una consecuencia desoladora: el arte descubre el fin del mundo en las horas destinadas a su realización. Este descubrimiento, sin embargo, termina protegiendo una posición conservadora - hasta el día de hoy- asociada con la exaltación de una subjetividad artística amenazada por las groserías de la temporalidad. Pero, en un contexto donde las imágenes sirven de síntoma a la normalización disciplinaria de los cuerpos y escoltan la atrocidad lábil del poder, la historia del arte se concentra en la idolatría sustancialista de la obra que colma el discurso estético de normas homogéneas y compactas. Escapando al presente para dominarlo con la distancia mítica del origen, el texto histórico se adueña de una duración irreal y demanda respeto por objetos sólidos, formas fijas, movimientos transparentes, verdades irrefutables. Una crítica frontal a esa postura realiza el historiador Carl Einstein:

Es a la vez penoso y humillante ver que los historiadores del arte consideran los hechos de la historia como fenómenos aislados: tratamiento que hace del arte un mundo monstruoso, adorado como un milagro divino [...] Las obras de arte nos preocupan únicamente en la medida en que ellas contienen medios susceptibles de modificar la realidad, la estructura del hombre y el aspecto del mundo. En otras palabras, el problema esencial reside para nosotros en esto: cómo la obra de arte se deja integrar en una concepción del mundo dada, y en qué medida ella la destruye o la supera. Así, la situación del historiador del arte se encuentra invertida [...] no basta ya con escribir la historia descriptiva o bien prestarse, como pontífices demagógicos, a apreciaciones estéticas o a censuras (cit. en Didi-Huberman, 251).

La conciencia de la temporalidad introducida por los movimientos racionalistas después del siglo XVIII destruye el orden natural y confiere a los hombres un poder desmedido y cruel; a su vez, los libera de la ilusión cíclica de un retorno y deteriora la hegemonía visual del arte al multiplicar imágenes encendidas de brevedad. El conflicto entre historia del arte y modernización, entonces, expresa el abismal tejido que lo conforma: la disputa por el sentido del tiempo. La primera, daría al pasado la oportunidad de volver a ocurrir - sin imitación o mágica convocatoria- a través de la interpretación crítica de las fuentes y los símbolos: aparece el tiempo unido al pensamiento para expropiar a la imagen lo que ésta no puede decir por sí misma. La segunda, acortaría la distancia entre los sujetos y el futuro - sin trucos técnicos o publicidad - redimiéndolo de su invisibilidad castradora: el tiempo convertido en premonición se anticipa a la muerte colocando en su interior mecanismos de control y flujo. De acuerdo a lo anterior la modernización desbarata las implicancias escatológicas ${ }^{5}$ que la historia del arte ampara y desplaza a la tradición artística del privilegio de la producción de imágenes verdaderas. La experiencia, reivindicada por la estética decimonónica como lugar de iluminación sublime y la expectativa, organizada por la economía-política moderna, se estrellan sin alcanzar un espacio común de cruce. La ruptura entre lo vivido y lo esperado — se podría argumen-

La filosofía de la historia post-hegeliana renuncia a una solución trascendental y convierte al tiempo en la sustancia narrativa de la sociedad. La historia del arte del siglo XIX rechaza los efectos de la modernización y su anuncio de la muerte de la naturaleza. Idealiza la época clásica, sobre todo el Renacimiento, con el afán de negar la ruptura epocal que se anuncia y defender la continuidad del espíritu creativo contra la actualización del movimiento, engañosamente presentada como futuro.

El modelo historiográfico utilizado por la escuela idealista alemana asume el fin de la naturaleza y el afán de recuperar su origen como dos instantes complementarios de una misma finalidad: lo absoluto. El arte es la única práctica que mantiene con la muerte una relación de sorpresa y trabajo que da autoridad a unas imágenes irrepetibles de lo gótico, melancólico, arqueológico, incognoscible y autoral. 
tar- profundiza la imposibilidad del ser humano de reencontrar su lugar entre la historia pasada y la historia futura. Las imágenes se convierten en experimentos destinados a suturar el conflicto y - aunque no logran una victoria duradera- facilitan un régimen visual híbrido donde se acumula lo viejo como una especie de archivo monstruoso, según Giorgio Agamben; y se volatiliza lo nuevo dejando restos impuros de mirada, según Walter Benjamin: «...El placer que brinda el mundo de las imágenes [...] se nutre de un sombrío desafío lanzado al saber» (127).

Las nuevas funciones epistémicas, económicas y políticas de la visualidad introducidas por el capitalismo moderno, disolvieron el «fundamento trascendental de la visión» y promovieron un espacio instrumental y disciplinario - indica Jonathan Crary- preocupado de capturar la atención óptica en un conjunto limitado, productivo y centralizado de cifras y operaciones. La racionalidad de lo perceptivo contribuyó a dar forma a una secularización del espacio figurativo con imágenes del alto tráfico y escasa permanencia. Sin duda que para los historiadores del arte la implosión de lo visual era un peligro ${ }^{6}$, una plaga icónica de ligera resonancia, pero que tenía la virtud de distraer de los «valores justos y perpetuos». La vanguardia artística, por su parte, al destruir las redes de significación y proponer el cinismo de los significantes parecía cumplir con el mismo objetivo: hacer reinar el terror en el lenguaje. Los juegos formales y las ironías estéticas rompían la vestidura clásica y entregaban a los dispositivos mercantiles nuevas estrategias escénicas para hundir a las masas en la novela del espectáculo. Imaginando una complicidad dura entre modernización y vanguardia, la historia del arte se encerró en un duelo terapéutico, basado en el rechazo a la experimentación, la nostalgia por el realismo ${ }^{7}$ y el desprecio de la cultura técnica.

Una parte importante del discurso artístico contribuyó a esquematizar la situación y fundar la leyenda de los dos ojos: el contingente y el inmortal. El primero, simple y fraccionario, observa una realidad construida por abstracciones y estadísticas, curiosamente presentada como objetiva; el segundo, complejo y analítico desmonta la representación con prácticas vanguardistas y alegorías. En este plano una concepción positivista del arte se hacía cada vez más débil, a pesar de la corona de cientificidad exhibida, la modernización otorgaba a las imágenes el trueno —espectáculo incandescente- y la borradura —el fin de la huella- donde se consumaba un exitoso proceso de desrealización. La condición empírica de los objetos artísticos no bastaba para certificar su estabilidad profunda y la filosofía de la historia no podía sostener un «más allá», seriamente cuestionado por una prognosis pragmática y comercial. Ya no se cumple la premisa kantiana de una moral de la naturaleza experimentada inocente y estéticamente, pues la imaginación es la potencia mercantil del pensamiento cuando éste, a su vez, es la planificación matemática del terror. La imagen articula la mímesis y la tiranía de lo existente desplazando al arte de la función de verdad que inauguró la Ilustración, pero lo existente encarna la instrumentalización de los cuerpos, la vigilancia y la domesticación de los afectos.

$6 \quad$ Es difícil afirmar una relación directa, pero sí creemos que los modelos de historia del arte desarrollados desde la segunda mitad del siglo XIX advirtieron la creciente dominancia de la «imagen técnica» y actuaron en conformidad con el deseo de ignorarla por su impronta pasajera o criticarla por su devaluación simbólica. La construcción metodológica — eje de la disciplina - se puede entender como una forma de resistir la influencia de emergentes áreas asociadas con la visualidad (el cine o la fotografía) y, a su vez, una estrategia para imponer el discurso estético-visual como la madre superior del análisis iconográfico. En el periodo de entreguerras corrientes realistas resistieron a los movimientos, formalistas, abstractos o conceptuales, como: Neue Sachlichkeit, Realismo Mágico, Pintura Metafísica y Novecento. 
El giro historiográfico de Erwin Panofsky ${ }^{8}$ puede leerse como negación de tal directriz. Abandonar esa fenomenología de la experiencia óptica — tan usada en las disciplinas artísticas - y a cambio establecer una antropología filosófica configurada por una urdimbre única y precisa donde lo heterogéneo no manifiesta su capricho, sino una parte del lienzo interno de la cultura. Lo factual se transforma en sentido. La vida material, deshecha por las rutinas del trabajo, parece no tener un texto donde dejar constancia de su paso, sobre todo, si la historia del arte centra la importancia en las grandes certezas del estilo y omite la arqueología cotidiana de los utensilios, los usos y los rituales. Erwin Panofsky, realiza un desplazamiento — desde la belleza al conocimiento- orientado a consagrar a las imágenes artísticas como un sustrato que muestra las huellas del saber humano y propone una teoría de la memoria: la supervivencia de un oscuro eco civilizatorio. $\mathrm{Al}$ respecto, Cassirer expresará que:

En el sentimiento estético se descubre una totalidad de conciencia y sus potencias, que es anterior a y se encuentra en la base de todo análisis de la conciencia en propensiones individuales, conectadas recíprocamente. En cada uno de estos modos de pensamiento [las leyes naturales y la experiencia estética], la totalidad de la que se ocupan se concibe, no tanto como la unión de sus partes, sino como si ella misma fuese el origen de sus partes y el fundamento de su determinación concreta (cit. en Podro, 227).

Buscando un punto de vista absoluto, el erudito alemán intentó reunir la diversidad de los fenómenos artísticos en una ficción heurística, donde juicio y experiencia; forma y contenido; objetividad y subjetividad se coordinaban entre sí alimentando una «idea regulativa» del arte. Podemos imaginar que esta arquitectura intelectual era una trampa epistemológica: implicaba el funcionamiento de la cultura como un sistema autónomo de fuerzas cognitivas reteniendo el mundo en símbolos, patrones y morfologías — aplicables a la producción artística- como una solución final, y a la vez, esas fuerzas cognitivas servían a la construcción de un proceso modernizador de estallidos y reconfiguraciones estéticas frecuentes. La respuesta a este problema, contraria a la ofrecida por la historia del arte positivista, es, para Erwin Panofsky, proponer una reconfiguración del campo historiográfico que libere al arte de las entropías modernizadoras, cuya destrucción de tradiciones termina alimentando un esquizofrénico deseo de monumentalidad. Ofrecer un contexto a la significación sin convertirla en historicismo hace del «método» iconológico un sistema analítico totalizador donde las imágenes son envueltas en "concordancias cronológicas» muy parecidas a los sistemas de pronósticos usados por la producción capitalista para coordinar la vida y su acontecer. La paradoja de fondo enreda a la historia del arte y la modernización en una lucha por el dominio del tiempo: «sólo posible porque hay estructuras formales en la historia que se repiten, aun cuando su contenido concreto sea en cada caso único y sorprendente para los afectados» (Koselleck, 80).

A pesar de la unidad descrita por Reinhart Koselleck, el deterioro de la mímesis es un rasgo distintivo del siglo XX y los intentos por detener su fuga solo agudizaron las con-

La pretensión teórica era certificar que el pasado deja — a pesar de su derrumbe - una escritura sistematizada, una serie de conexiones simbólicas que permiten volver a él. A través de un sistema de conceptos aplicados — rigurosamente- a las obras de arte aparecen las dimensiones objetivas y subjetivas junto con los modos de hacerse visibles. Lo anterior debe ser examinado por una visión crítica basada en tomar posición fuera del tiempo histórico analizado, sin negar la historicidad del problema, y mostrar cómo los artistas o los historiadores releían las tradiciones anteriores a ellos y las resignificaban en el marco cultural de su época. 
tradicciones entre representación y sentido: con ello la idea del tiempo lineal y compacto se marchitó ante las críticas y demandas de visiones anacrónicas, surrealistas, discursivas e ideológicas. Los historiadores del arte — durante la primera mitad del siglo XX- intentaron resolver la manifiesta ambigüedad de los límites artísticos ante la imposibilidad de situarse éstos en relación con alguna verdad. La validez mimética perdía sus garantías argumentativas, en la misma medida que la historiografía positivista no podía demostrar la existencia de un orden transhistórico fundado en orígenes y fuentes respetables. La modernización ampliaba sus fueros y avanzaba más allá de ser la expresión material del desarrollo económico y la innovación científico-tecnológica, pues su capacidad de mediatizar lo simbólico la volvía un lenguaje y una política. La tensión entre los fragmentos erráticos producidos por la violencia del progreso y los principios constructivos para orientar su marcha hicieron aún más difícil la conciliación entre arte e historia; mientras uno veía en lo singular la marca indiscutible de una subjetividad soberana y resistente a la enajenación, el otro no podía imaginar la significación estética sin organizarla en un sistema. La escritura estaba separada de su objeto...

¿Qué nuevos saberes sobre la capacidad óptica del cuerpo humano trajo consigo la modernización y cómo afectaron la narrativa estética — ya consciente- de la mecanización de las imágenes? La visión, dirigida por saberes neurofisiológicos, cuánticos y matemáticos ${ }^{9}$, se convirtió en una lógica formal y fue separada de la experiencia y el espectador, fomentando valores abstractos, estadísticos y cuantificables. La percepción asumió un estatus científico y antropológico distante de consideraciones de estilo o gusto. Las imágenes dependían de máquinas limpias y exactas cuya relación con la realidad era de circulación y obsolescencia. Estos cambios incidieron en la historia del arte y la configuraron como una disciplina afecta a la dinámica modernizadora: las teorías evolucionistas y sus modelos de desarrollo temporal; la aparición de museos y colecciones unidas a técnicas documentales y consagración de monumentos; el consumo global de copias, gracias a la reproducción en serie, justificaron la aparición de sistemas explicativos en el arte. El volumen y la confusión visual exigían ofrecer interpretaciones distintivas entre las imágenes estéticas y las técnicas. Sin embargo, la búsqueda de la originalidad o la restauración de un orden exento de fragmentos y mercancías; el anhelo por conservar una supremacía cultural dentro del huracán productivo del capitalismo llevó a la historia del arte a mitificar la relación entre tiempo, discurso y obra. A través de la organización visual del pasado se presentó al arte como la única autoridad espiritual de lo unitario y autorreferencial ${ }^{10}$. Mientras la tosca cultura de masas estimulaba un sensorium - construido por el espectáculo y la libido- cuya energía se destinaba a gastar y sustituir, el arte buscaba un principio regulador con el cual someter la deformidad de la actualidad a las serenas planicies del juicio universal. «Pero el idealismo filosófico — acota Theodoro Adorno- no era tan partidario de la espiritualización estética como la construcción haría pensar. Más bien se presentaba como el defensor de lo sensorial que era consumido

9 Los estudios psicológicos sobre la sensación de Gustav Fechner fueron decisivos para imponer en la mentalidad científica del siglo XIX una concepción analítica, mensurable y casi termodinámica de la funciones de la visión.

10 Esta respuesta, en todo caso, reconoce con tristeza la aparición de una ruptura con las ideas de totalidad y unicidad, a favor de lo discontinuo. El siglo XIX es fundacional y reclama un texto nuevo para sí: el progreso. El arte que simpatiza con estos objetivos es pasajero y trivial, ha perdido el don de unir las cosas y habla desde los retazos, las instantáneas y la comodidad. No es casual que Morelli, Warburg o Panofsky obvien la figura de Charles Baudelaire o del impresionismo. 
por la espiritualización; esa teoría de lo bello como la aparición sensorial de la idea era, en palabras del propio Hegel, afirmativa en tanto que apología de lo inmediato como algo que tiene sentido...» (126).

Los historiadores del arte querían resolver el dilema estético hegeliano de una actividad necesaria, pero imposible. Si la modernidad era una máquina de tiempo compuesta por miles de sincronizaciones, dispositivos y automatismos tendientes a repetir lo mismo, entonces, la mirada había perdido la capacidad de reconocer la diferencia. Erwin Panofsky, aventuramos, supuso que las tendencias artísticas de vanguardia contribuían a homologar el arte con la modernización y, por lo tanto, validaban lo formal - sin consistencia- rompiendo la unidad fundamental entre objeto y época. Por medio de un trabajo sistemático de revelación de capas, de retiro de ruinas, se lograba reconstruir esa grave lengua que ata la superficie a un destino:

El historiador del arte tendrá que comprobar lo que él cree que es el significado intrínseco de la obra, o grupo de obras a las que dedique su atención, contra lo que él crea que es el significado intrínseco de tantos documentos de civilización, relacionados históricamente con aquella obra o grupo de obras como pueda dominar: documentos que testifiquen sobre las tendencias políticas, poéticas, religiosas, filosóficas y sociales de la personalidad, período o país que se estén investigando. No es necesario decir que, a la inversa, el historiador de la vida política, de la poesía, de la religión, de la filosofía y de las instituciones sociales debería hacer un uso análogo de las obras de arte. Es en la búsqueda de los significados intrínsecos o contenido donde las diferentes disciplinas humanísticas se encuentran en un plano común en vez de servir de siervas la una de la otra (Panofsky, 24).

De acuerdo a lo anterior, la actitud historiográfica de la escuela alemana manifestó una contradicción irresoluble: construir un modelo cronológico del arte para suturar las grietas internas del pensamiento en el umbral anacrónico de la modernización.

Las imágenes artísticas eran dueñas de una perturbadora latencia: devolvían las memorias enterradas en su cuerpo figuracional y desgarraban la representación al mostrar significados no previstos y legibles únicamente con las modernas técnicas de interpretación cultural. La obra podía reducirse a la porfía del espíritu o expandirse en la sedimentación y la fractura de signos incapaces de llenar la totalidad simbólica. El régimen escópico (Jay, 2003) establecido por el capitalismo, al contrario, orientó las funciones de la visión hacia lo inmediato y escenográfico, dejando sin esperanza al pasado, abriéndolo a múltiples exhibiciones patrimoniales o museísticas atadas a la condición referencial del lenguaje. La modernización no destruyó la concepción positivista de la historia, la utilizó para legitimar su continuo y borrar las caídas, interrupciones y descalces que impidieran establecer la formación visual de lo social. De esta manera, también, buscó en el arte las señales del progreso y patrocinó obras fundadas en la ilusión de la belleza, la simetría y un devenir cosificado. La mirada participó en la estrategia del capitalismo para convertirse en lengua de la vida cotidiana y realizar un proceso estético donde funde al museo, la industria cultural y la vanguardia en una sola cerámica de múltiples brazos. La imagen es el producto central de la monopolización de la subjetividad y se expresa en un objeto complejo que lleva consigo la obediencia - como diría Adorno- con las formas de la rebelión.

El supuesto teórico de Erwin Panofsky radica en la sobrevivencia de lo no dicho—aunque presente- en las operaciones simbólicas de un periodo. Es una materia ciega protegida por la communitas, que entrega lo desconocido de sí misma al término de su existencia. 
De esta forma preserva la memoria arrojándola hacia adelante donde otros hombres y mujeres, encontrarán las interpretaciones justas para revelar los acontecimientos. Hay una excesiva confianza en la capacidad del lenguaje de atrapar lo posible y convertirlo en evidencia. Al confrontar el pasado con una actualidad rota por sus fumigaciones económicas, pareciera que emerge una ética desde el fondo de la cultura que el historiador puede narrar: «La imagen, en tanto, investidura del cuerpo verdadero, se convierte en el medio de su nueva presencia en la que el cuerpo es inmune al tiempo y a la mortalidad» (Belting, 190).

La historia del arte enfrentada a la lectura de las imágenes debió elegir entre ser un abanico - desplegándose sobre la textura de lo discontinuo- o un espejo — refractándose en un delirio de alteridad-. Erwin Panofsky asumió el espejo y consagró una epistemología de los orígenes causalista y totalizante, que logró una doctrina perturbadora: censuró la lucha iconológica con sus desafueros y desarticulaciones y rearticuló el pasado con sus síntomas y montajes. Así, la historia del arte dejó de ser la monografía decrépita del positivismo y se convirtió en una memoria crítica de la modernización.

\section{REFERENCIAS}

Adorno, Theodor. Teoría Estética. España: Editorial Akal, 2004. Medio impreso.

Agamben, Giorgio. El hombre sin contenido. México: Ediciones Altera, 2005. Medio impreso.

Ankersmit, Frank. Historia y Tropología. Ascenso y caída de la metáfora. México: Fondo de Cultura Económica, 2004. Medio impreso.

Belting, Hans. Antropología de la Imagen. España: Editorial Katz, 2007. Medio impreso.

Benjamin, Walter. Discursos Interrumpidos I: Sombras Breves. Madrid: Editorial Taurus, 1982. Medio impreso.

Crary, Jonathan. Las Técnicas del Observador. Madrid: Editorial Cendeac, 2008. Medio impreso.

Didi-Huberman, Georges. Ante el Tiempo. Historia del arte y anacronismo de las imágenes. Buenos Aires: Adriana Hidalgo Editora, 2008. Medio impreso.

Jay, Martin. Campos de Fuerza. Argentina: Editorial Paidós, 2003. Medio impreso.

Koselleck, Reinhart. Aceleración, Prognosis y Secularización. España: Editorial Pretextos, 2003. Medio impreso.

Panofsky, Erwin. La perspectiva como forma simbólica. Barcelona: Editorial Tusquets, 1973. Medio impreso.

—. Estudios de Iconología. Madrid: Alianza Editorial, 2002. Medio impreso.

Podro, Michael. Los Historiadores del arte críticos. Madrid: Editorial Visor. La Balsa de la Medusa, 2001. Medio impreso.

Recepción: 20 de enero de 2010

Aceptación: 1 de marzo de 2010 